\title{
Producing Value Out of the Invaluable: A Critical/Cultural Perspective on the Live Streaming Industry in China
}

\author{
Sheng Zou
}

Stanford University, United States, shengz@stanford.edu

\begin{abstract}
This paper extends the critique of informational capitalism to increasingly commercialised cyberspace in China by examining the case of live streaming. Informed by Marxist and neo-Marxist theories, I set out to investigate how live streaming ushers in flexible paid labour online, and how informational capitalism cashes in on users' affective engagement, locking them into a constant process of value production. Diving into the structure and affordances of live streaming platforms as well as users' practices, I argue that live streaming in China manifests an emerging trend of capitalist enclosure in cyberspace, which has dire implications for people's subjectivities and interactions. Three major implications are discussed, namely the reconfiguration of time and space for the production of value; the instrumentalisation of affects, bodies and human interactions; and the erosion of users' freedom and individuality.
\end{abstract}

Keywords: informational capitalism, live streaming, instrumental rationality, commodification, digital labour

Acknowledgement: I would like to thank the reviewers and the editor for their helpful comments and suggestions. Many thanks also to Ban Wang for his feedback on an earlier draft of the paper.

\section{Introduction}

Once upon a time, the Internet, in its inchoation, was envisaged as an emancipatory and disembodied space where free-spirited individuals could construct virtual communities of their own choosing. The utopian vision of Internet technology is best captured by Barlow (1996) when he proposed, in his Declaration of the Independence of Cyberspace, "a new home of Mind" that is naturally independent of the traditional tyrannies of the industrial world.

However, the era of Web 2.0 has witnessed the growth of hyper-commercial social media; and the term 'social networking' has been reduced to empty marketing rhetoric. The apparently spontaneous and free interactions of online users, subsumed under the logic of informational capitalism, are co-opted as novel forms of labour and vehicles of value production. Marxist and neo-Marxist critiques on capitalism become relevant again in a whole new technological context. Despite their discrepancies and disagreements, Marxist and various strands of neo-Marxist (or postMarxist) theories may be partially combined to provide a deeper and holistic understanding of different dimensions of informational capitalism.

In particular, I seek to critically examine how informational capitalism cashes in on users' affective engagement and locks them into a constant process of value production through the case of live streaming in China. My main research questions are as follows:

1) What kind of economy does the Chinese live streaming industry sustain?

2) What are the affordances and structure of Chinese live streaming platforms, and how do they shape users' practices? 
3) What are the implications of live streaming in China for the production of value and for people's subjectivities and interactions?

In the following, I first briefly revisit neo-Marxist theories on audience activities to situate live streaming within a broader theoretical framework with emphasis on commodification and labour (Section 2). I then delve into the affordances and structure of Chinese live streaming platforms, delineating the ways in which they enable the production of value and the workings of informational capitalism (Section 3). Subsequently, three major implications of live streaming in China are discussed, namely the reconfiguration of time and space for the production of value (Section 4); the instrumentalisation of affects, bodies and human interactions (Section 5); and the erosion of users' freedom and individuality (Section 6).

\section{Theorising Online Activities: The Digital Audience as Commodities and La- bour Force}

Digitisation has largely reshaped the boundary between producers and consumers, between professionals and amateurs, giving rise to a radically more participatory audience, who not only consume but also produce (Bruns 2008).

However, a unilateral emphasis on audience agency might obscure the structuring power of digital media beneath the façade of audience empowerment. As Freedman $(2012,88)$ puts it, "far from signaling a democratisation of media production and distribution, 'prosumption' is all too often incorporated within a system of commodity exchange controlled by existing elites". The oligopoly of digital giants has re-ignited (neo-) Marxist critiques in the field of media and communication.

Inspired by Marxism, two strands of critical theories that engage with the issue of informational capitalism are influential in the area of media and communication. One is the audience-as-commodities tradition pioneered by Canadian scholar Dallas Smythe. Extending Marxist analyses, Smythe (1981) expounds on the functioning of the advertising-supported media system, where audience are turned into commodities sold to advertisers. The audience's predictable attention and demand becomes productive and valuable. Underlying this process is the exploitation and alienation of the audience commodity.

In the Marxist theory of alienation, workers are not only deprived of the ability to claim ownership over the products of their own labour, but also lose the ability to determine their own actions. According to Smythe $(1977,20)$, mass media produce three kinds of alienation, namely "alienation from the result of their work [...] alienation from the commodities-in-general which they participate in marketing to themselves [...] and alienation from the labour power they produce and reproduce in themselves". This argument of alienation is applicable to the discussion of digital audiences' engagement with new media platforms.

Another influential strand of thought is associated with the Italian autonomist Marxists, in particular with the writings on immaterial labour (Lazzarato 1996; Hardt and Negri 2004). Immaterial labour can be "both intellectual and affective labour, which involves a number of activities that would not be considered work in Fordist work environments" (Wittel 2012, 321). In Hardt and Negri's $(2004,108)$ formulation, it "creates immaterial products, such as knowledge, information, communication, a relationship, or an emotional response".

Informed by this tradition, Terranova (2004) develops the concept of "free labour". From this standpoint, online activities, such as participation on social media, translate into "productive activities that are pleasurably embraced and at the same time often shamefully exploited" $(2004,78)$. Free labour is pervasive on open platforms that 
Scholz $(2017,1)$ characterises as "simple-to-join" and "anyone-can-play" - platforms that are at once playgrounds and factories.

The two strands of critical media theories problematise the techno-optimistic conception of audience activity as a sign of democratisation and empowerment. They both reveal that the apparently empowered audience are subjugated to subtle forms of exploitation and monetisation.

To build upon these theories and arguments, I propose that digital technologies not only bring forth various forms of free labour, but also flexible forms of paid labour - in line with Sennett's (2006) depiction of the post-industrial society, where jobs become more flexible arrangements. Live streaming in China constitutes a prime example of flexible yet precarious paid labour online, where streamers get compensated for their affective work.

In addition, the Frankfurt School of Critical Theory further contributes to the theorising of informational capitalism (Fuchs 2012). Their ideological critiques could help explain how consumers are caught up in the process of exploitation, or even actively embrace the reign of the capitalist logic. It is ideological control over consumers that serves to reproduce the capitalist relations of production. Horkheimer's (1947) notion of instrumental reason and Marcuse's (2002/1964) concept of technological rationality lend useful insights into the process whereby interactions between users are reduced to instrumental acts of value exchange. Lukács' (1972) discussion of reification also provides a fruitful entry point to the analysis of the audience's role in the culture of prosumption.

In the following section, I draw on relevant theories to analyse how informational capitalism shapes new forms of flexible paid labour online through the case of live streaming in China, a society undergoing ever-deepening marketisation in its media and cultural scene.

\section{Live Streaming Platforms in China: Structure and Affordances}

As a global phenomenon, live streaming takes off in different societies with locally distinct manifestations, subject to the interplays between various global, regional and local influences. Live streaming in post-communist China is extremely commercialised, with built-in features of direct monetisation.

The Chinese live streaming industry came into full bloom in 2015. Differing from traditional video sites, live streaming apps/sites enable real-time and interactive communication between streamers and viewers, shoring up a sense of co-presence. According to an iiMedia research report (2016), more than 200 live streaming apps/sites were launched during 2015, attracting 200 million users. Many of these platforms are private enterprises that rely on venture capital investment. A 2018 report released by the China Association of Performing Arts reveals that the live streaming industry gained 30.45 billion RMB (4.42 billion USD) in revenue in 2017 (Sohu 2018). Sources of revenue include direct payment from users, advertising, membership fees, e-commerce, and so on. The rapid growth of the live streaming industry fits in with China's market-oriented cultural system reform since 2008.

There are different types of live streaming, such as game streaming, talent shows and life-casting. Streamers of various kinds attract viewers with their appearance, performance and conversations, in exchange for both mental satisfaction and monetary returns. With an emphasis on life-casting, I set out to delineate the structural design of live streaming platforms, and how they function to facilitate digital forms of capitalist production and accumulation. My theoretical analysis is supported by partic- 
ipant observation on two popular live streaming apps, Inke and Xian Dan Jia (XDJ hereafter).

Live streaming apps/sites are usually structured around chat-rooms or live channels, each hosted by a unique streamer. Once the viewer opens a live streaming app/site, they will see lists of different channels represented by the streamers' profile pictures - usually 'beautified' versions of their selfies. By clicking on the profile icons, they will enter a chat-room where a streamer is chatting or performing. Viewers can post messages via the textbox at the bottom of the screen; they also have the option to reward the streamer with virtual gifts or red packets. The system displays the realtime number of simultaneous viewers in the chat-room, as well as the rewards that the streamer receives. In the following, I will identify some key structural elements and affordances of live streaming apps/sites, so as to clarify how the capitalist logic is built inside the interface of these platforms.

\subsection{Virtual Gifts and Red Packets}

Different platforms invent different systems of symbols to represent varying levels of rewards. On XDJ, for instance, viewers use virtual red packets as a type of symbolic capital to reward the streamers they like; Inke offers additional virtual gifts such as virtual cars and yachts. Both types of symbolic capital are directly deposited into the streamers' accounts on the platform. Symbolic as they seem, these virtual items are purchased by the viewers with actual money.

Virtual items make manifest the attempt to mask the monetary transactions between users. The irony of live streaming platforms lies in the fact that they seek to sustain a commercial economy by refusing to recognise it on the surface. Instead, platforms hide the transactions and schemes of monetisation behind the cloak of a "gift economy" (Barbrook 1999). In the gift economy - as a different regime of value to the commercial economy - people do not use money as the basis of valuation; rather, the emphasis is on the maintenance of relationships and bonds. Red packets, in particular, are part of a well-accepted Chinese tradition of gift-giving. The amount of monetary rewards on live streaming platforms ranges from two yuan (RMB) to over a thousand yuan. Symbolic meanings are assigned to particular amounts based on their pronunciation in Chinese (e.g. 52.0 yuan, signifying 'I love you', and 131.4 yuan, meaning 'love lasts forever'). The deployment of both traditional and popular cultural symbols is meant to gloss over the profiteering agenda.

The monetary rewards that streamers garner from their viewers do not wholly go into their own pockets. Platforms develop different profit-sharing schemes. By their own account, streamers only get a designated portion of the gross income, with terms set by the company. The rest of their income goes to the company that runs the platform. There may be rules or restrictions as to when and how a streamer can withdraw money from their accounts. That said, for top-performing streamers, it is still a lucrative business.

\subsection{Live Streamer as a "Performing Self"}

To earn virtual gifts and red packets, many streamers spare no effort in pandering to their viewers' voyeuristic desire and curiosity. They often groom and stage themselves carefully before appearing in front of their audience. Zhang and Hjorth (2017) shed light on the work that female streamers do in front of webcams, which involves "applying make-up before livestream, adjusting other paraphernalia, twisting the programmes, being social during the stream itself, interacting with fans off-stream and so forth" $(2017,8)$. It is noteworthy that male streamers can be the target of voyeuris- 
tic gaze as well. XDJ, in particular, features predominantly male streamers who put great effort into maintaining an appealing image.

Their practice speaks to Featherstone's (1982) notion of the "performing self", which captures how individuals self-consciously monitor their own performance, their appearance and their bodily demeanour. Although live streaming may be used in many ways and for many purposes, it is primarily used for entertainment purposes in China. There are various types of live streaming performance; compared to game streaming and live talent shows, life-casting is particularly intimate insofar as it entails the sharing or exhibition of mundane activities such as consuming food, preparing meals, exercising in gyms or even sleeping. Bedrooms, hotel rooms and even bathrooms become live streaming studios.

The streamers imagine themselves to be micro-celebrities (Marwick 2013), narcissistic and yearning for self-validation. They not only wish to hear compliments from their fans, but also expect monetary rewards. Their needs for self-actualisation, sociality and pleasure are intricately intertwined with materialistic desire. It is a routine practice for them to greet each new entrant to the chat-room, and to intimately thank those who reward them. Many streamers request compensations straightforwardly; others may promise to perform certain tasks in exchange, which could even border on erotic performances. Despite the platforms' apparent prohibition of 'illicit' forms of performance, such as nudity, streamers are often allowed to perform their sexuality in more subtle and implicit ways in order to lure viewers. The platforms often promote streamers with high 'yan zhi' (a Chinese buzzword indicating level of attractiveness); their attractive faces and bodies become central to the appeal of the platforms.

\subsection{Promotion and Ranking of Streamers}

Platforms regularly give visibility to a subset of streamers either by promoting them on the homepage or by ranking them according to their earnings. Inke has sections called 'newbies' and 'recommendations' on its interface to showcase selected streamers; XDJ has a 'trending' tab that promotes top-performing streamers. Streamers promoted by these algorithms are mostly young and good-looking. Topperforming streamers' profile pictures are often featured on the homepage. Working with the platform, live streaming incubators and agencies have also mushroomed: these serve to discover, train and promote streamers with potential.

Additionally, some platforms such as XDJ develop daily and weekly charts to rank streamers by the rewards they achieve. Viewers are also ranked according to the amount they spend. Within a typical XDJ chatroom, top spenders' profile icons are displayed on the left-hand side of the screen. To reinforce the ranking system, platforms often develop a level-system, where both streamers and viewers climb the ladder as they earn or spend more. This evaluation system creates incentives for users to maintain their contributions to the platforms.

The structure and affordances of live streaming platforms enable the workings of informational capitalism. In the following section, I propose three implications of hyper-commercial live streaming in China: namely the reconfiguration of time and space for the production of value; the instrumentalisation of affects, bodies and human interactions; and the erosion of users' freedom and individuality.

\section{Reconfiguring Time and Space for the Production of Value}

Informational capitalism ushers in a new configuration of time and space that facilitates new modes of value production in the digital age. As Harvey $(1996,222)$ posits, social constructions of space and time often "change to accommodate new material 
practices of social reproduction, new ways of assigning values". For instance, innovations in transportation and communication technologies facilitate instantaneous international transactions, accelerate the turnover time, and shrink the felt distance between people, hence the "time-space compression" (Harvey 1996, 242). Harvey's thesis of time-space compression - and his spatio-temporal theory of capitalism was not intended for the discussion of the Internet and social media. However, time and space are important dimensions through which to conceptualise the transformation of informational capitalism. It is instructive to appropriate this spatio-temporal lens in relation to digital economy. In the era of Web 2.0, a more portable, accessible and seamless experience of digital media makes possible a novel regime of production. The reconfiguration of spatio-temporalities constitutes the basis for the establishment of value within the digital economy.

Looking at the digital world, Agger $(2011,120)$ proposes that the advent of smartphones creates a different modality of time, "iTime", that fundamentally alters "the pre-internet boundaries between public and private, day and night, work and leisure". Smartphones, in this sense, not only bring about a technological change in human communication, but an ensemble of shifting experiences with time and space.

\subsection{Redefining 'Work Time' and 'Free Time'}

According to Marx (1867), the value of a commodity is measured by the labour time necessary to produce that particular commodity. Surplus value is "the substance of unpaid labour-time" $(1867,672)$, which is appropriated by capitalists. Although digital labour increasingly assumes immaterial or symbolic forms, the Marxist theory of value based on labour time is still relevant, especially in the case of live streaming: the more time streamers spend on the platform, the more viewers they attract, and the more transactions they generate, allowing for the accumulation of capital.

Labour process in the digital age is no longer bound by business hours or physical workspace, but may unfold anytime and anywhere. The distinction between paid and unpaid work time is blurred. Work time devoted to the screens can seamlessly blend into private communication and apparently leisure activities such as online chatting and messaging.

This reconfiguration of time and space updates Marx's explanation of labour. In Capital, Marx (1867) implies a domain of life outside commodification, namely private life. In the post-Fordist digital age, even the private domain of leisure is colonised, as capitalism produces ever more false needs that must be satiated (Marcuse 2002/1964). The new modality of time, compatible with Web 2.0, is portable and elastic (Agger 2011, 124), attaching people (especially Internet-savvy young people) constantly to their devices and the online platforms on which they connect, interact and co-produce.

Both Smythe's and the Italian autonomists' arguments provide useful insights into the restructuring of time under the logic of capitalism. Critiquing the advertisingsupported mass media industry, Smythe $(1977,3)$ proposes that audience have been turned into commodities sold to advertisers, and that "the non-sleeping time of most of the population is work-time". In the classical Marxist view, although leisure time is related to the production, reproduction and repair of labour power, it does not directly produce values, thus differing from work time. In Smythe's formulation, the boundary between leisure time and work time becomes porous, as consumers in effect perform marketing functions for the producers of goods through their exposure to advertising. The commodity, in this case, is audience-consumers' attention, which potentially translates into purchasing behaviour. This perspective on work time reveals a dialec- 
tical conceptualisation of consumption and production, in which each propels and produces the other.

On a related note, Italian autonomist Marxism contends that work has shifted from factories to the social realm, hence the term "social factory" (Tronti 2013/1962). In this sense, the leisure time that users spend interacting with each other on digital media platforms becomes work time, not just because they are sold to advertisers, but because they contribute both content and value to the platforms (without being compensated).

In this light, the notion of free time becomes an illusion. In fact, even sleeping time is turned into work time. Live streaming platforms afford a $24 / 7$ world which users can access without time limits, where "sleep has no necessity or inevitability" (Crary $2013,21)$. It is a world that "decrees the absoluteness of availability, and hence the ceaselessness of needs and [...] their perpetual non-fulfilment" $(2013,21)$. Some streamers go so far as to keep their camera on while sleeping in order to 'work' without pause. Sleep, in this case, ceases to be the antithesis of work, but is colonised and harnessed by the logic of accumulation, or converted into something from which value can be extracted.

When streamers are telling the viewers that they will be on camera for just a few minutes, they often say, "I'm going to broadcast for just two yuan". What is particularly intriguing about this detail is the conversion of the temporal dimension into the monetary dimension. In this case, money as a yardstick of value is also used as a measure of temporality. Time is instrumentalised under the logic of accumulation. This is reminiscent of Lukács' $(1972,90)$ conception of time, which indicates that "time sheds its qualitative, variable, flowing nature [...and] freezes into an exactly delimited, quantifiable continuum filled with quantifiable 'things'". This detail speaks to how time, value and labour are intricately and commensurately interwoven.

\subsection{The Commodification of Intimate and Interstitial Spaces}

Mobile technology also symbolically produces mobile bodies that navigate different spaces. Mobile network interactivity allows users "to shop, work, and socialise without leaving the physical space of the home" (Andrejevic 2003b, 148). With the aid of webcams, the grassroots use of surveillance technologies readily transforms domestic activities in the private and intimate realm into a form of value-generating labour.

Exploring how mobile commerce and reality TV turn space into an object of consumption, Andrejevic (2003b, 137) argues that surveillance has expanded "to embrace all spaces of human activity, thereby rendering all spaces productive from the perspective of capital". The complex and diverse spaces on the screen are reduced to recordable texts to be exploited. The spatial expansion of surveillance potentially puts people to work 'on the go'.

Live streamers addicted to the platform keep their cameras on almost anytime and anywhere, not only revealing their activities at home, but also their travels outdoors. Many of them use extendable selfie sticks to hold their phones in front of their faces when they are walking in the streets, visiting tourist attractions or doing outdoor activities. The spatial surroundings become objects of consumption, as they meet the viewers' curiosity; they are part of the streamers' strategy of 'brand differentiation', setting the streamers apart from competitors.

During this process of over-sharing, the geographical data that users submit in exchange for customisation become assets for the platforms. The live streaming platforms collect users' geographical data so as to group them by locations. This geographic categorisation is used as a strategy to increase streamers' relevance to 
viewers, based on the assumption that people would like to connect with those in their vicinity.

The omnipresence of surveillance saturates all spaces, including interstitial or fragmented spaces. As Liu (2014) argues, fragmented spaces - namely interstices between larger systematic domains such as workplaces, schools and homes - used to be the blind spots of capitalist production; however, with the advent of mobile media and the rise of peep culture, these interstices are increasingly encroached on by the logic of production and are extracted for value. In addition, Liu observes that spaces are increasingly de-ritualised in the digital age, meaning that the conventional reliance of rituals and traditions on spaces is reduced. In live streaming, for instance, red packets - which used to be given only upon special occasions - are frequently exchanged on the screen of mobile devices. The activities organised around people's spatial data on live streaming platforms, such as connecting with people nearby or joining location-based virtual groups, eventually turn all spaces into objects of social production.

\section{The Instrumentalisation of Affects, Bodies and Human Interactions}

Life-casting entails strategic self-presentation, intimate disclosure of one's personal life, and affective interactions with viewers in exchange for monetary rewards. It shows how informational capitalism is gradually and quietly colonising and instrumentalising human bodies, affects/emotions, libidos, and interactions, leading to the disintegration of the ideal of a "whole person" (Clark 2011).

A non-instrumental conception of the human harks back to the Romantic tradition, which opposes the destructive tendencies of market-based economy and industrialism. Romanticism appeals to "notions of nature and the natural as norms of health, vitality or beauty and as precisely what commercial/industrial society represses or destroys, both in the human psyche and in the surrounding environment" (Clark $2011,13)$. At the core of the Romantic conception of human is "psychic or cultural wholeness", or "the concept of an originally healthy, fulfilled or unalienated human nature that modern society is understood to have suppressed, divided or distorted and that needs to be restored" $(2011,16)$. With the capitalist overvaluation of rationality at the cost of spontaneous bonds between people, the 'whole' person is fractured by the domination of a market economy as the only means of assessing human work and things. The workings of consumerism and late capitalism, with the concomitant new markets of desires and lifestyle choices, further fashion the human self into a hedonistic consumer.

How does live streaming undermine the wholeness of a person? It subjugates individuals and their interactions to a kind of instrumental rationality. Weber (1978/1921) distinguishes between formal (or instrumental) rationality and substantive rationality. Formal/instrumental rationality "break[s] down human meaning", or "'disenchant[s]' the lifeworld, leading to value fragmentation, meaninglessness, and automaton-like human behaviour" (Gunderson 2015, 226). Weber's distinction has great influence on the Frankfurt School. Horkheimer $(1947,3)$, for instance, contends that in modern societies rationality is formalised to the extent that social action can only be judged in reference to self-interest and usefulness. This kind of instrumental rationality is governing users and their practices on live streaming platforms in three ways.

First, live streaming subjugates users' libidos, affects and emotions to the calculative hold of instrumental rationality. Emotions in the capitalist consumer culture become "things" that are managed, monitored, manipulated or manufactured 
(Hochschild 1983); they are put to work by the rational imperatives and marketoriented dictates of late capitalism. Consumer desire, apparently an autonomous emotional longing, is largely structured and directed by the industry to which it turns for satisfaction. On live streaming platforms, users' affective interactions are instrumentalised and leveraged for monetisation. Affect, as Negri (1999) predicts, emerges as the basis for a new alternative conception of value, especially in the economy of attention that involves the interactivity of the users of communication services. Following Negri's lead, Arvidsson and Colleoni $(2012,135)$ propose an "affect-based law of value", which indicates that the business model of digital media is "based primarily on the capacity to initiate and sustain webs of affective relations". Although they disagree with the premise of the Marxist labour theory of value, I see their contribution as complementary - rather than antagonistic - to Marxist labour theory. Value not only reflects the amount of labour time, but also the qualities of labour power (Hermann 2009). Different streamers, for instance, produce varying degrees of value, largely based on the perceived qualities of their idiosyncratic affective labour. Meanwhile, they, as well as the digital media companies, thrive on attracting and objectifying viewers' affective investments, such as comments, follows and shares. Online sentiments are transformed into exploitable data and into a kind of capital. People's desires and affects are not their own, but "part of the capitalist infrastructure" (Smith 2007 , 24). The blurring boundary between work and leisure inserts pleasure into instead of separating it from - labour processes. In traditional capitalist production, pleasure, or Eros, is repressed so that energy can be directed toward serious work (Marcuse 1955). In the digital economy, pleasure or libidinal drive is subsumed under the capitalist logic of accumulation.

Second, live streaming alienates and reifies human bodies under the voyeuristic gaze. Featherstone $(1982,18)$ argues that through the proliferation of stylised body images, consumer culture "encourages the individual to adopt instrumental strategies to combat deterioration and decay". Images of sexual and attractive bodies, associated with pleasure, hedonism, leisure and display, emphasise the importance of appearance. Featherstone divides the body into two dimensions, inner and outer; and it is the latter, that is, the appearance and the movement of the body, that becomes the focus of users' attention. In the reign of consumer culture, body is "proclaimed as a vehicle of pleasure" $(1982,21)$ : the closer a particular body approximates idealised images of youth, fitness and beauty, the higher its exchange-value. This equation invites the unashamed display of the human body. Compatible with this logic of hedonistic consumption, body is conceptualised as plastic, which - with the effort of maintenance and building - may be moulded into a desired shape that fits in with the mediatised ideals. The work of maintenance and building corresponds to a conceptualisation of the body as a machine-like property. The body, under the voyeuristic gaze, becomes divorced from the 'whole person'. It becomes a thing that requires deliberate investment and cultivation. Under a "wholly fetishistic and spectacular logic", what one ought to do is "to form it into a smoother, more perfect, more functional object for the outside world" (Baudrillard 1998, 132). The body is "reappropriated", not for the autonomous ends of the subject, but to meet capitalistic objectives, in particular "hedonistic profitability" $(1998,132)$. Accordingly, beauty becomes a form of capital, disenchanted and de-sublimated. The attractive and often eroticised body becomes "nothing more than sign material being exchanged" $(1998,133)$. On live streaming platforms, streamers often use 'beautified' selfies as profile pictures, and narcissistically exhibit their bodies to the viewers. The platforms offer them a beautifying tool (mei yan) that gives special lighting and radiance to their faces. It is in this 
context that the body becomes a sign and disintegrates into fragments - into something that is no different from other functional objects.

Third, live streaming undermines the authenticity of human interactions, as it stages and fashions a "performing self". The streamers that present their bodily images through webcams recall Benjamin's (2008) discussion of the cameraman, who annihilates the distance between the viewers and the viewed. In Benjamin's allegorical analogy, a cameraman is different from a painter, in that the "painter maintains in his work a natural distance from reality; the cameraman penetrates deeply into its web" $(2008,233)$. Likewise, through the technology of live streaming, the "performing self" presents itself up close to the viewers, manipulating the latter's feelings through tactical representation and communication. Following the previous point of reification, not only are bodies reified in such interactions, but so also are social relationships, as the commodity form is extended to more aspects of social life. Consequently, "a relation between people takes on the character of a thing" (Lukács 1972, 697); and the exchange value overshadows the original meaning of this relation. In live streaming chat-rooms, generous spenders are often playfully dubbed 'gold owners'. Streamers treat top-ranked "gold owners" differently by talking to them more frequently and intimately, or even by performing particular tasks upon their requests. Some streamers share their private contact information with generous spenders for off-stream interactions. Their intimate response becomes a service, "surrounded by waves of fake spontaneity, 'personalised' language, orchestrated emotions and [...] 'functionalised' human relations" (Baudrillard 1998, 163).

Horkheimer and Adorno's (2002) critique of cultural industry rings true for the case under discussion: "the most intimate reactions of human beings have become so entirely reified" $(2002,136)$. In the consumerist space, overflowing with services and goods, the role of money - as a standardising measure of value and a basic form of social power - is heightened. The domination of "gold owners" in the chatrooms is manifested not only in their interactions with streamers as service-providers, but also in the hierarchy between big spenders and 'free-riding' viewers, who are treated differently in the same chat-room.

\section{The Erosion of Freedom and Individuality}

\subsection{The Illusion of Freedom in the Consumerist Marketplace}

In the techno-optimistic vision of the Internet, online users are free-willed and autonomous economic subjects capable of making their own decisions. This may seem to be the case in live streaming: the streamers are allowed to decide how long they 'work', and the viewers are offered a dazzling array of choices as to whom to watch. However, at a structural and ideological level, this freedom is illusory. Fundamentally, the users are not free from their desires, which are largely shaped and manipulated by the media companies. Streamers constantly feel the urge to stay longer in order to get more rewards and to attract more viewers; viewers endlessly dwell on the platforms, possessed by their voyeuristic and libidinal drive while captivated by the sensually appealing menu constructed by digital media companies. Their enjoyment is transformed into "surplus-enjoyment" (Kordela 2017, 48), which "like capital, is never satisfied in itself and always strives for more of itself".

This scenario aligns with the Frankfurt School's argument that monopoly capitalism turns citizens into passive consumers who are remarkably compliant with the capitalist system. In particular, Marcuse's (2002/1964) diagnosis of the "onedimensional man" in the consumer society could be extended to the current discus- 
sion. The one-dimensional man has lost his individuality, freedom and agency, plagued by false consciousness and blind to his true needs, for his needs are administered and superimposed. According to Marcuse, "the most prevailing needs to relax, to have fun, to behave and consume in accordance with advertisements, to love and hate what others love and hate, belong to this category of false needs" $(2002 / 1964,7)$.

The one-dimensional man pays a price for the satisfaction of these needs by surrendering his freedom and authentic individuality. As consumer culture integrates individuals into the capitalist system, the private space is being "whittled away by a society which shapes aspirations, hopes, fears and values, and even manipulates vital needs" (Kellner 2002, xxvii). The touted benefits, such as liberation and freedom, become "subtle instruments of domination which serve to keep individuals in bondage to the system that they strengthen and perpetuate" (Kellner 2002, xxxi). In short, in the one-dimensional society, subjects are docile and submissive, because their independence of thought, their autonomy and their right to opposition are thwarted, even if their (superimposed) needs are satisfied. Their freedom is structurally delimited: they have the freedom to choose on the predetermined menu, but not the freedom "from being controlled by economic forces and relationships" (Marcuse $2002 / 1964,6)$. Marcuse's analysis offers an ideological explanation of how the capitalist system works to reproduce labour power and relations of production. Profitdriven media, with their techno-optimistic marketing rhetoric, seek to nurture belief in the capitalist system. The goal is to ensure that the subjects do not challenge this system, and thereby perpetuate this arrangement.

In this environment, top-down panoptic control is not needed; the individuals survey themselves as a way to extract surplus value (Mules 2001). Attention-capturing techniques such as self-branding constitute technologies of subjectivity, or ways for people to govern themselves in the framework of neoliberal capitalism (Marwick 2013).

Admittedly, the streamers could choose whether or not to enter into a contract with the platform. Nonetheless, this is often a forced choice between either submitting themselves as data commodities to the platform, or being denied the possibility of benefiting from online interactions while staying away from the platform. Once they turn themselves into commodities with market values, they are no longer in total control of their own images, actions and data shadows, or how these are used by the platform.

\subsection{Standardisation, Commensuration, and the Loss of Authentic Individuality}

In their critique of cultural industry, Horkheimer and Adorno $(2002,94)$ argue that "culture today is infecting everything with sameness" due to the constant process of identifying, cataloguing and classifying. This argument could be appropriated to conceptualise the functioning of digital media. Intuitively, digital media provide an open channel for the unbridled expression of one's idiosyncratic individuality; that is often what the marketing rhetoric suggests. However, Illouz $(2007,83)$ reveals that selfpresentation online is "plagued by the problems of homogeneity and standardisation". In her study of online dating sites, she finds that "the sheer volume of interactions forces one to develop standard techniques of management" (Illouz 2007, 83).

Live streaming constitutes a similar case. In the digital economy of attention, where goods and services abound while attention is scarce, one is forced to use standardised techniques to improve efficiency and maximise viewership. In order to improve their performance, streamers often submit to the standard of beauty by 
working on and investing in their bodies, and by using the technological tool available to enhance their looks. Their profiles are more likely to converge; so are the techniques they use during live streaming.

Admittedly, some degree of differentiation is needed; and streamers are certainly not identical in their appearance. However, such differences, under the capitalist logic, are appropriated as a strategy of brand differentiation to produce more variety rather than diversity. Furthermore, brand differentiation does not challenge the standardised archetypes or homogenisation at a higher level. The relationship between homogenisation and differentiation is not one of opposition, but of complementarity (Huxley 1969). Product differentiation works within homogenised categories, and actually serves to make standardisation less visible and more appealing to viewers.

Another central mechanism promoting standardisation is the ranking system, which provides a metric for the valuation of labour. As Marx (1867) remarks on the fetishism of commodities, labour is reified and reduced to a common denominator when different products are equated as values, and different kinds of labour abstracted and homogenised accordingly. The valuation process disregards particular kinds of human labour. Thus, the prices of commodities alone determine the magnitude of values; the common expression of all commodities in money alone establishes their characters as values. The ultimate money form of commodities conceals the social character of private labour and the social relations between individuals. Commodities are evaluated and compared predominantly according to their exchange value. In Lukács' $(1972,88)$ words, this heralds a "trend toward greater rationalisation, the progressive elimination of the qualitative, human and individual attributes of the worker".

The notion of commensuration - namely "the comparison of different entities according to a common metric" (Espeland and Stevens 1998, 313) - is central to the workings of ranking systems. By forcing distinct entities into comparisons, "commensuration transforms qualities into quantities, difference into magnitude, constructing proxies for uncertain and elusive qualities" $(1998,314)$. When qualitative differences become quantitative ones under the rubric of commodification, "people become means, things become ends" $(1998,320)$. One of the underlying assumptions of commensuration is the relativity and comparability of value, which "denies the possibility of intrinsic value, pricelessness, or any absolute category of value" $(1998,324)$.

As live streaming platforms rank streamers and viewers, qualitative differences among the users are obliterated in the one-dimensional ranking chart. The characters, traits, and uniqueness of individuals recede beneath the comparable money values, and everyone becomes commensurable and comparable, objectified and reified on a common metric. Marcuse $(1998,45)$ observes that under the technological rationality, "individual achievement has been transformed into standardised efficiency", with "the individual's performance [...] motivated, guided and measured by standards external to him". According to him, when individuals have their respective characters quantified, they become mere crowds, namely "an association of individuals who have been stripped of all 'natural' and personal distinctions and reduced to the standardised expression of their abstract individuality" (Marcuse 1998, 53). A crowd is different from a community, because it merely gathers atomic subjects of self-preservation oriented toward their own selfish interests and impulses $(1998,53)$. Their 'personality' becomes merely a means for attaining instrumental ends. Along this line, it could be argued that there are only crowds on live streaming platforms, not communities. Not only are the relationships between subjects instrumentalised, 
but the subjects themselves are also reified as standardised commodities governed by external laws and exchange values.

\section{Conclusion}

Live streaming in China constitutes an intriguing example of how the capitalist logic is encroaching on previous digital 'commons'. The instrumental rationality of capitalist accumulation is ceaselessly colonising various parts of the social life. To circle back to the initial research questions, it is clear that live streaming in China sustains a commercial economy cloaked in the aura of a gift economy. With built-in features of monetisation (e.g. red packets and virtual gifts) as well as means of commensuration and standardisation (e.g. ranking charts), live streaming platforms set in motion a continuous cycle of value production, one that blurs the boundary between leisure and work and creeps into intimate and interstitial spaces. Live streamers - enslaved by instrumental rationality - produce surplus value for digital platforms by performing "the work of being watched" (Andrejevic 2003a), and by strategically fashioning their self-presentations and trading on social interactions. On the other hand, the viewers' affective and monetary investments are also appropriated. With the illusion of freedom, both streamers and viewers are unknowingly compromising their self-control and autonomy.

Is this capitalist colonisation inevitable? It is only inevitable if the humans harnessing the technology intend it to be. If technologies and platforms continue to be warped toward market value, they will drift further away from other kinds of values. The term 'value' could be defined in multiple ways - as economic value, moral value, social value, public value, to name just a few (Bolin 2011; see also Fuchs 2012). It could refer to "the ultimately good, proper, or desirable in human life", or market value "measured in quantitative terms" (Wittel 2012, 325; see also Graeber 2001). The capitalist colonisation of the social sphere replaces other types of values with market value, or extracts value from the invaluable - such as emotions, affections and bodies - to which no price tag should be attached. The commercial economy is overwhelming other types of economies. Admittedly, there are still spaces online based more on gift economies, or devoted to alternative subcultural practices. It is an empirical question as to how long these spaces will remain intact. Although it would seem naïve to suggest a return to a utopian cyberspace free from commercial forces, it becomes increasingly urgent to protect and carve out spaces for these alternative practices before they are reconstructed by the instrumental logic of capitalist production and accumulation.

\section{References}

Agger, Ben. 2011. iTime: Labour and Life in a Smartphone Era. Time \& Society 20 (1): 119136.

Andrejevic, Mark. 2003a. Reality TV: The Work of Being Watched. Oxford: Rowman \& Littlefield.

Andrejevic, Mark. 2003b. Tracing Space: Monitored Mobility in the Era of Mass Customization. Space \& Culture 6 (2): 132-150.

Arvidsson, Adam and Elanor Colleoni. 2012. Value in Informational Capitalism and on the Internet. The Information Society 28 (3): 135-150.

Barbrook, Richard. 1999. The High-Tech Gift Economy. In Readme! Filtered by Nettime: ASCII Culture and the Revenge of Knowledge, edited by Josephine Bosma, 132-138. New York: Autonomedia. 
Barlow, John. 1996. A Declaration of the Independence of Cyberspace. Accessed January 10, 2018. http://doc.cat-v.org/political science/cyberspace-declaration-of-independence

Baudrillard, Jean. 1998. The Consumer Society: Myths and Structures. London: Sage.

Benjamin, Walter. 2008. The Work of Art in the Age of Mechanical Reproduction. London: Penguin Books.

Bolin, Göran. 2011. Value and the Media. Cultural Production and Consumption in Digital Markets. Farnham: Ashgate.

Bruns, Axel. 2008. Blogs, Wikipedia, Second Life and Beyond: From Production to Produsage. New York: Peter Lang.

Clark, Timothy. 2011. The Cambridge Introduction to Literature and the Environment. Cambridge: Cambridge University Press.

Crary, Jonathan. 2013. 24/7: Late Capitalism and the Ends of Sleep. London: Verso.

Espeland, Wendy N. and Mitchell L. Stevens. 1998. Commensuration as a Social Process. Annual Review of Sociology 24 (1): 313-43.

Featherstone, Mike. 1982. The Body in Consumer Culture. Theory, Culture \& Society 1 (2): 18-33.

Freedman, Des. 2012. Web 2.0 and the Death of the Blockbuster Economy. In Misunderstanding the Internet, edited by James Curran, Natalie Fenton and Des Freedman, 69-94. New York: Routledge.

Fuchs, Christian. 2012. Dallas Smythe Today - The Audience Commodity, the Digital Labour Debate, Marxist Political Economy and Critical Theory. Prolegomena to a Digital Labour Theory of Value. Triple C: Communication, Capitalism \& Critique (2): 692-740. Accessed January 10, 2018. http://www.triple-c.at/index.php/tripleC/article/view/443

Goffman, Erving. 1969. The Presentation of Self in Everyday Life. London: Allen Lane.

Graeber, David. 2001. Toward an Anthropological Theory of Value: The False Coin of Our Own Dreams. New York: Palgrave.

Gunderson, Ryan. 2015. Environmental Sociology and the Frankfurt School 1: Reason and Capital. Environmental sociology 1(3): 224-235.

Hardt, Michael and Antonio Negri. 2004. Multitude: War and Democracy in the Age of Empire. London: Penguin.

Harvey, David. 1996. Justice, Nature and the Geography of Difference. Oxford: Blackwell.

Hermann, Christoph. 2009. Value and Knowledge: Insights from Marxist Value Theory for the Transformation of Work in the Digital Economy. Rethinking Marxism 21: 2, 275-289.

Hochschild, Arlie R. 1983. The Managed Heart: The Commercialization of Human Feeling. Berkeley, CA: University of California Press.

Horkheimer, Max. 1947. Eclipse of Reason. New York: Continuum.

Horkheimer, Max and Theodor Adorno, 2002. Dialectic of Enlightenment: Philosophical fragments. Stanford, CA: Stanford University Press.

Huxley, Aldous. 1969. Brave New World. New York: Harper \& Row.

iiMedia Research Institute. 2016. Chinese live streaming industry encounters setback in 2016 (in Chinese). Accessed June 28, 2018: http://www.iimedia.cn/42373.html

Illouz, Eva. 2007. Cold Intimacies: The Making of Emotional Capitalism. Oxford: Polity Press.

Kellner, Douglas. 2002. Introduction to the Second Edition. In One-Dimensional Man, by Herbert Marcuse, xi-xxxviii. London: Routledge.

Kordela, A. Kiarina. 2017. The Subject-Object of Commodity Fetishism, Biopolitics, Immortality, Sacrifice, and Bioracism. Cultural Critique 96: 37-70.

Lazzarato, Maurizio. 1996. Immaterial labour. In Radical Thought in Italy: A Potential Politics, edited by Paulo Virno and Michael Hardt, 133-150. Minneapolis: University of Minnesota Press.

Liu, Tao. 2014. Social Media and Social Production of Space: A Contemporary Interpretation of Michel Foucault's Theory of Space Discipline. Chinese Journal of Journalism \& Communication (in Chinese). 36 (5): 49-63.

Lukács, Georg. 1972. History and Class Consciousness. Cambridge, MA: MIT Press. 
Marcuse, Herbert. 2002/1964. One-Dimensional Man. London: Routledge.

Marcuse, Herbert. 1998. Technology, War and Fascism: Collected Papers of Herbert Marcuse (Volume 1), edited by Douglas Kellner. London: Routledge.

Marcuse, Herbert. 1955. Eros and Civilization. Boston, MA: Beacon Press.

Marwick, Alice. 2013. Celebrity, Publicity, and Branding in the Social Media Age. New Haven, CT: Yale University Press.

Marx, Karl. 1867. Capital: Volume I. London: Penguin.

Mules, Warwick. 2001. That Obstinate Yet Elastic Natural Barrier: Work and the Figure of Man in Capitalism. M/C: A Journal of Media and Culture 4 (5). Accessed January 10, 2018. http://www.triple-c.at/index.php/tripleC/article/view/379

Negri, Antonio. 1999. Value and Affect. Boundary 26 (2): 77-78.

Scholz, Trebor. 2017. Introduction to Digital Labour: The Internet as Playground and Factory. New York: Routledge.

Sennett, Richard. 2006. The Culture of the New Capitalism. New Haven, CT: Yale University Press.

Smith, Daniel W. 2007. Deleuze and the Question of Desire: Toward an Immanent Theory of Ethics. Parrhesia 2: 66-78.

Smythe, Dallas W. 1981. Dependency Road: Communications, Capitalism, Consciousness, and Canada. Norwood, NJ: Ablex.

Smythe, Dallas W. 1977. Communications: Blindspot of Western Marxism. Canadian Journal of Political and Social Theory 1(3): 1-27.

Sohu.com. 2018. Chinese live streaming industry development report, 2017. Accessed June 28, 2018. http://www.sohu.com/a/217448191 528296

Terranova, Tiziana. 2004. Network Culture: Politics for the Information Age. London: Pluto Press.

Tronti, Mario. 2013/1962. Factory and Society. Operaismo in English. Accessed August 21, 2018. https://operaismoinenglish.wordpress.com/2013/06/13/factory-and-society/

Weber, Max. 1978/1921. Economy and Society: An Outline of Interpretive Sociology. Berkeley: University of California Press.

Wittel, Andreas. 2012. Digital Marx: Toward a Political Economy of Distributed Media. tripleC: Communicaiton, Capitalism \& Critique 10 (2): 313-333. Accessed January 10, 2018. http://www.triple-c.at/index.php/tripleC/article/view/379

Zhang, Ge and Larissa Hjorth. 2017. Live-streaming, Games and Politics of Gender Performance: The Case of Nüzhubo in China. Convergence: the International Journal of Research into New Media Technologies. Published online. Accessed January 10, 2018. http://journals.sagepub.com/doi/abs/10.1177/1354856517738160

\section{About the Author}

\section{Sheng Zou}

Sheng Zou is a Communication PhD candidate at Stanford University. His research interests include critical/cultural theory, audience participation, media representation, and globalisation of media, as well as digital culture in China. 